Rachael Gibson, Toronto / Harald Bathelt, Toronto

\title{
Field configuration or field reproduction?
}

\author{
The dynamics of global trade fair cycles
}

\begin{abstract}
This paper builds on discussions about field-configuring events (FCEs) and cyclical/temporary clusters by investigating the role of trade fairs in structuring processes of knowledge creation in an industry or technology field. It argues that while fundamental field-configuring activities, such as shifts in technological trajectories, are not typically associated with trade fairs, these events play an important role in field reproduction through decentralized processes of knowledge exchange and learning, supported by the global cycles of events. Yet, knowledge flows across different events are rarely as continuous and fluid as in an ideal-type cyclical cluster context. Despite some overlap in their goals and audiences, different trade fairs generally serve different functions and are characterized by diverse knowledge practices. This is illustrated through an empirical analysis of the global trade fair cycle of the lighting industry, which is based on semi-structured interviews and systematic observations conducted at three international/national trade fairs: LightFair International (USA), IIDEX/NeoCon Canada and Light + Building (Germany). From this, we suggest that most trade fairs establish a permanent middle-ground between, but quite distant from, the extreme ideal-types of discrete field-configuration and continuous knowledge circulation.
\end{abstract}

Keywords: cyclical clusters, field-configuring events, field reproduction, global trade fair cycles, knowledge generation, temporary clusters, trade fairs

\section{Introduction}

In an economic context, trade fairs are widely recognized as important events where products are sold, business leads generated and contracts negotiated. In the past decade, however, such events have increasingly been viewed as temporary sites for exchanging vital knowledge about particular industry or technology fields. Related to the notions of temporary clusters or temporary markets (BATHELT et al. 2014), this interpretation develops a knowledge-based perspective, which emphasizes the role of trade fairs in stimulating knowledge flows between geographically distant firms (BORGHINI et al. 2004; MASKELL et al. 2006; BATHELT/SCHULDT 2010; RinALLO/ GOLFETTO 2011). Such knowledge flows are a consequence of the interactions between exhibitors and potential buyers (typical visitors), as well as discussions with atypical visitors - i.e., those attendees who do not plan to make purchase decisions during the trade fair (BORGHINI et al. 2006). Atypical visitors include competitors, suppliers and knowledge brokers/intermediaries, such as architects and designers in the case of the lighting industry. Whereas knowl- edge transfers during trade fairs focus to some extent on market-related knowledge, they also include a wider diversity of knowledge flows, ranging from production to innovation to the political/regulatory context.

Recent work has described trade fairs as fieldconfiguring events (FCEs) that can spur fundamental changes in a particular industry (LAMPEL/ MEYER 2008). Such events are important not only in terms of their material impact on the industry, but also in terms of their broader symbolic effects (SCHÜSSLER et al. 2014). In the context of specific industry or technological fields, the study of FCEs aims to elucidate the processes underlying the interaction of agents in a common space where different ideas for innovation are explored (SCHÜSSLER et al. 2014). It is not entirely clear, however, whether the FCE concept accurately captures the dynamics of trade fairs. Do trade fairs really stimulate more fundamental technological and institutional changes, or do they serve to reflect and reproduce such changes?

The literature on temporary clusters offers some guidance here. It suggests that when the agents 
of a particular value chain or technology field meet at trade fairs, they become involved in intensive processes of communication and observation. A trade fair is, however, just one piece of a complex puzzle, as the agents - firms, executives, managers and technical specialists - are involved in on-going processes of interaction that extend well beyond one specific get-together (COHENDET et al. 2013). Aside from utilizing other communication tools, such as online social networks and regular producer-user meetings, agents regularly attend numerous trade fairs in different regions and countries and at different times of the year (e.g. NorCLIFFE/RENDACE 2003). The recurrent character of such meetings speaks directly to the concept of cyclical clusters (PoweR/JANSSON 2008), which draws our attention to important issues of sequencing and connectedness in knowledge creation processes across different trade fairs.

Yet, our trade fair research raises some important questions regarding the likelihood of cyclical field evolution or deliberate field configuration during such events. Previous studies of national/international trade fairs suggest that the nature of knowledge exchanges and the collective sense-making processes at these events often operate in a decentralized and incremental manner (Schuldt/Bathelt 2011). On the one hand, these events do not seem to create spaces across which continuous knowledge circulation takes place, as a rigid cyclical-cluster interpretation would suggest. On the other hand, they do not normally trigger more fundamental, organized changes in a technology/industry field comparable to an ideal-type FCE context. In fact, what we routinely observe is a middle-ground that is clearly situated between, but quite distant from, either of these two extremes. In analyzing the roles of FCEs and cyclical/temporary clusters in the context of national/international trade fairs, we aim to shed some much needed light on the conceptual debate regarding temporary knowledgeexchange platforms and how they play out during national/international trade fairs.

Taking the abovementioned issues as a starting point, this paper explores the relationships and dynamics among trade fairs in a particular technology/industry field - namely, the lighting industry. We directly compare two North American business-to-business fairs focused on lighting and related products: IIDEX/NeoCon Canada 2008 in Toronto (Canada) and LightFair International (LFI) 2009 in New York (U.S.). To supplement these cases, we also draw from previous research on a major international lighting fair in Europe: Light + Building 2004 in Frankfurt/Main (Germany). Our discussion is based on systematic observations and semi-structured interviews conducted with exhibiting firms at these events. The empirical inquiry was structured by the concept of the temporary cluster, through which we analyzed knowledge exchange practices during the events. From this, we aim to elucidate the primary functions and goals of these lighting fairs, the nature of knowledge exchange processes and the extent to which these fairs demonstrate field-configuring or cyclical capabilities.

The next section provides a stylized overview of the literature on cyclical clusters and field-configuring events in order to demonstrate that trade fairs are better defined as loosely connected events that facilitate field reproduction, rather than field configuration. Then the data and methods used in the paper are described. The section that follows presents and discusses our empirical findings, focusing on the functions of the trade fairs investigated, the goals of the participating firms and the attendant interaction and knowledge-creation processes. We conclude the paper by suggesting that knowledge flows during trade fairs are more likely to contribute to decentralized processes of on-going field reproduction, rather than field configuration.

\section{Field-configuring events and global trade fair cycles}

The notion of the "periodic social economy" (e.g. NorCLiffe/Rendace 2003) is applicable to almost any trade fair, regardless e. g. of its focus, size or international character. Yet, more recent work in organizational and management studies has defined trade fairs in terms of field-configuring events (FCEs) (LAMPEL/MEYER 2008), which comprise microcosms (MEFFERT 1993; RosSON/SERINGHAUS 1995) of a nascent industry, market or technology field. FCEs are defined as "temporary social organizations" (LAMPEL/ MEYER 2008) or "settings in which people from diverse social organizations assemble temporarily, with the conscious, collective intent to construct an organizational field" (MEYER et al. 2005, 467). Based on LAMPEL/MEYER's (2008) original work, the core features of FCEs may be summarized as follows: i) they bring together in one location agents which are organizationally 
and geographically diverse; ii) their duration is limited, ranging from a few hours to a few days; iii) they create opportunities for unstructured face-to-face interactions; iv) they rely heavily on ceremonial and/or dramaturgical activities; v) they are a platform for collective sense-making and knowledge transfer; and, vi) they assist in the development of social and reputational resources, which can be used in other contexts and for other purposes.

This conceptualization stands in contrast to other approaches focusing on the evolution of fields, which tend to focus mainly on "global and continuous processes [...] while paying little attention to discontinuous and localized processes such as field-configuring events that play an important, albeit intermittent, role in shaping the evolution of fields" (LAMPEL/MEYER 2008, 1027). It is for this reason that we find the FCE concept particularly interesting and innovative as it aims to go beyond conventional discussions of field evolution or structuration. Indeed, LAMPEL/ MEYER (2008, 1028) suggest that the study of such events reflects a "reorientation of research on field evolution towards mechanisms of institutional change that lack temporal continuity."

While field-configuring events may shape and also be shaped by the development of a field (LAMPEL/MEYER 2008), it is the capacity of FCEs to instigate fundamental changes in an entire industry that appears to be at the core of the concept - and such changes often take place in a planned and highly organized manner. The contributions in the 2008 special issue of the Journal of Marketing Studies on FCEs, organized by LAMPEL/MEYER (2008), clearly illustrate this emphasis. And it is this aspect of the original FCE concept that serves as the primary focus of our analysis here. ${ }^{1}$

That being said, the FCE concept is both broad and ambiguous. Similar to "temporary clusters" (MASKELL et al. 2006) and other forms of "organized proximity" (TORRE/RALLET 2005), FCEs are temporally and spatially restricted in the sense that participating agents are co-located for a limited period of time - from a few hours to, at most, a few days (LAMPEL/MEYER 2008). Like temporary clusters, FCEs offer many opportunities for intensive face-to-face interaction, which enables knowledge creation and diffusion. The notion of FCEs has been applied in a variety of different research contexts. It has been used, for instance, to describe award ceremonies and fes- tivals (e.g. AnAND/WATSON 2004; ANAND/JONES 2008; RÜLING/PEDERSEN 2010), professional gatherings and conferences (e.g. MCINERNEY 2008; HARDY/MAgUiRE 2010; SCHÜSSLER et al. 2014), and even speed contests in the automobile industry (RAO 1994).

While the definition of FCEs is very open, numerous applications of the concept refer to events that are purposely planned, highly structured and/or hierarchically organized. These types of events are expected to enable the development of shared understandings regarding new technological or institutional innovations that potentially shape the future direction of a specific organizational field (GARUD 2008; MöLLERING 2010). In this body of literature, FCEs are viewed as mechanisms through which organizationally and spatially disparate agents learn about common challenges, share informational resources, coordinate activities and strategies and ultimately shape the structural development of a field (ANAND/Jones 2008). Yet, despite its increasing popularity in the management and organization studies literature, the concept of FCEs remains vague. Aside from terminological differences, it is not always clear what distinguishes FCEs from, for instance, "temporary clusters" (MASKELL et al. 2006) or "tournament rituals" (Moeran/Pedersen 2011). While the concept could feasibly be applied to local folk festivals or exhibitions (e.g. MoERAN/PEDERSEN 2011), processes of field configuration are in such cases limited to the local field - and only a minority of local events can be expected to actually have such a strong impact. They would not have wider consequences on industries or technologies in an international context. This is not to suggest that such field configuration is impossible in other, larger events. Indeed, research on fairs in the fashion industry (ENTWISTLE/ROCAMORA 2006; RinAllo/GolfETTO 2006), for instance, clearly documents the ways in which specific trade fairs and fashion events can influence, and even create, entire fashion trends through so-called concertation processes (RINALLO/GOLFETTO 2006). These concertation processes specifically relate to the role of powerful industry associations and trade fair organizers, who are responsible for planning and executing consensus-building activities regarding trends in materials, colors and design for the upcoming fashion season. The resulting consensus is later converted into code books, which are distributed to trade fair participants well in advance of the events. These code books are used as the basis for the development 
of new fashion products, which are presented by exhibiting firms at upcoming fashion fairs. Thus, the latest fashion trends of a particular season are the result of a highly structured field-configuration process that configures the future field of the industry.

At a broader level, however, very few trade fairs operate in the same way as fashion fairs (SChuldT/Bathelt 2011). While it is true that trade fair organizers always have a direct impact on who participates, how exhibits are organized, and which firms dominate the scene (BATHELT et al. 2014), their direct influence rarely extends to the realm of knowledge creation. In many large industry events, knowledge flows occur in a decentralized manner due to the complexity and multifaceted nature of participant interactions. Such loose get-togethers do not easily correspond with pre-structured events that intend to configure a field. While LAMPEL/MEYER (2008, 1028) suggest that FCEs "are both the products and drivers of field evolution", the capacity to fundamentally shape an industry or technology field seems highly limited in the majority of trade fairs. This is not to downplay the significance of these events in shaping industry dynamics; rather, it is to suggest that the vast majority of fairs influence their field in largely decentralized, unpredictable and incremental ways (e.g. SchÜSSLER et al. 2014). They do not trigger field configuration. Furthermore, the act of determining the field-configuring capabilities of an event is largely a retrospective endeavor. Indeed, the actual impact on the field cannot be concluded until after the fact, given that participants may or may not adhere to the directions of the organizers. Möllering's study (2010) of a technology-focused engineering conference offers valuable insights into such processes.

Power/JANSSON's (2008) work emphasizes an additional, different dimension related to the cyclical nature of trade fairs and to the limitations of treating them as singular events. Indeed, as far back as medieval times, merchants travelled from fair to fair (ALLIX 1922) and created "networks of fairs" (MOERAN 2011). Each industry has multiple trade fairs occurring in different places that make up a cycle of events where overlapping technical communities come together repeatedly over the year and from one year to the next, thus enabling ongoing knowledge circulation and cumulative knowledge creation in a particular industry. While the cyclical nature of trade fairs and their recurring character are indeed important characteristics, empirical evidence of ongoing knowledge circulation and strongly connected sense-making processes regarding the same group of actors remains weak. In fact, there is very little empirical evidence to suggest that trade fairs in a particular industry or technology field are necessarily connected in a close or meaningful way.

Many fields feature numerous and varying types of trade fairs - from hub shows to import/export fairs, and from global to national, regional or local events. Even when focusing on events characterized by a strong international focus, we still find comparable events in different geographical locations that differ substantially in their functions and goals. Because of this diversity, a high level of overlap in the group of participants who attend these events is unlikely. This is particularly true of small and medium-sized firms, who, for various reasons, often attend only a few events in close proximity to their home market. And, while global players regularly present at all major events in an industry, these firms often send different representatives with different specializations that best correspond to the needs of the particular events. This makes it very difficult for different types of knowledge to be systematically collected, bundled and disseminated within multinational corporations and between trade fairs. While this does not mean that radically new knowledge is not transmitted through large corporate organizations, it does highlight the challenges of distributing tacit and contextual knowledge in such concepts.

These considerations imply relatively decentralized, unplanned and unstructured processes of knowledge generation at trade fairs (BATHELT/ GIBSON 2013), with repeated discussions about the same topics, trends and news in the respective field. These processes tend to support the ongoing reproduction of a field through practices of knowledge exchange and circulation. This is done in a decentralized fashion guided by individual sense-making in the collective environment of the events, as well as collective sense-making shaped by collective impressions during the events and carried out afterwards in the individual home offices. We use the example of the lighting industry below to illustrate that the sequences of trade fairs in an industry or technology field serve to enable ongoing field reproduction rather than active field configuration; but our findings may be extended to other industries as well (e.g. Schuldt/Bathelt 2011). 
In sum, we suggest that trade fairs can be understood as field-reproducing events ${ }^{2}$, due to the on-going often incremental manner in which they shape and reshape the development of firms, industries and technology fields. This process of shaping and reshaping is highly decentralized, rather than proceeding through a centralized/ planned agenda-setting process. While there is certainly overlap regarding the groups of firms and sometimes even the executives or technological specialists that participate in such events, this type of overlap is limited, restricting the systematic diffusion of trade-fair-related knowledge beyond the local context. Important innovations, market trends and regulatory changes represent recurrent topics at all types of trade fairs and, thus, are more easily disseminated among different corporate branches and localities around the world because of the repetition involved, coupled with the specific functions of the events and ongoing digital and relational knowledge flows between them. These processes are significant because they reduce the need for constant meetings and organized exchanges to keep everyone up-to-date about key developments in the field, particularly in the context of large multinational firms.

While this paper does not include an in-depth discussion of the processes of sense-making, it compares the overarching character of different fairs, the different goals of exhibitor participation, the nature and extent of knowledge exchange processes, and the impact of these events on the lighting industry as a whole. These analytical foci assist in detecting differences among the fairs and allow us to empirically document the relative dearth of relationships and lack of direct knowledge flows across the events. While the results illuminate the limited field-configuring capabilities of these events, they demonstrate their contribution to ongoing field reproduction.

\section{Data and methodology}

Our study investigates the goals and knowledge circulation practices of exhibiting firms at international trade fairs in the lighting industry. Using a qualitative approach, we aim to deepen our understanding of the character of these events by exploring the linkages between the fairs and the extent to which they might establish a wider trade fair cycle in the lighting industry. The analysis focuses specifically on the nature and degree of the interactions among exhibitors as well as their stated goals of participation. The empirical setting consists of two lighting fairs in North America - the LightFair International (LFI) in New York and IIDEX/NeoCon Canada in Toronto - with some additional qualitative insights drawn from a major international lighting fair in Germany - Light + Building in Frankfurt/ Main $^{3}$. All of the trade fairs are considered leading events in the lighting industry in their respective national contexts. A brief overview of each is provided below (BATHELT et al. 2014).

LightFair International (LFI). LFI is an annual design-oriented trade fair. It is widely regarded as the most important event targeting the architectural and commercial lighting industries in North America (LightFair International 2009a, $2009 \mathrm{~b}$ ). It is larger and more clearly focused on the lighting industry than IIDEX, but it is substantially smaller than L $+B$. Every year its host location alternates between Las Vegas and New York. Despite its prominence in the U.S., LFI is a mid-sized fair like IIDEX; in 2009, it attracted 513 exhibitors and approximately 23,000 visitors. The composition of international participants is much less pronounced than at $\mathrm{L}+\mathrm{B}$. In 2009, about three quarters of the exhibitors $(76.6 \%)$ and an even higher proportion of visitors came from the U.S. Despite having a fairly strong international representation, LFI has a clear focus on the North American market.

IIDEX/NeoCon Canada. IIDEX is an annual trade fair that includes multiple aspects of the built environment, with a particular emphasis on architectural, lighting and interior design elements (IIDEX/NeoCon Canada 2008a, 2008b). In this sense, it is somewhat eclectic, rather than focusing solely on the field of lighting. IIDEX is the largest event of this kind in Canada, with approximately 16,000 visitors and 391 exhibitors in 2008. IIDEX mainly attracts attendees from Canada, the majority of which come from Southern Ontario. In 2008, most of the exhibitors were from Canada (about $75 \%$ ), with many of the foreign firms originating from the U.S. manufacturing belt. Foreign exhibitors were often represented through Canadian-based branches, subsidiaries or partners; comparatively few representatives came from these firms' home bases. IIDEX is clearly directed toward its own national market in Canada. Compared to LFI and L+B, it is therefore difficult to characterize IIDEX as an international or hub trade fair; rather, it is best described as a regional/national event. 
Light + Building $(\mathrm{L}+\mathrm{B})$. $\mathrm{L}+\mathrm{B}$ is by far the largest of the three fairs. It takes place every two years and, in 2004, boasted 1,920 exhibitors and approximately 116,000 visitors. The diverse geographical origins of attendees provide some indication of $\mathrm{L}+\mathrm{B}$ 's role as a global hub and of its central position in the lighting industry. When we conducted our research, more than half of the exhibitors $(56.9 \%)$ and almost three quarters of the visitors $(72.0 \%)$ came from outside of Germany (Messe Frankfurt GmbH 2004a, 2004b). $\mathrm{L}+\mathrm{B}$ is an important venue for exchanging information about institutional and technological changes, with a strong innovation component (BATHELT/SCHULDT 2008).

The selected trade fairs allow us to characterize and compare the main functions of event sequences, the goals of participation, as well as the nature of knowledge circulation processes. By including trade fairs from both Canada and the U.S., we can make cross-national comparisons and observe the potential dynamic connections between these trade fairs. Although $\mathrm{L}+\mathrm{B}$ will not be directly compared to these events, key insights from our research at this fair will be added wherever appropriate to further illustrate our findings.

Since we are primarily interested in the behavior of firms, rather than the firm representatives, we made a concerted effort to interview top-level executives, including owners and senior managers who could speak on behalf of their firms. While this was relatively easy in the case of small- and medium-sized firms, it was more challenging to reach senior-level executives in large multinational firms. Nevertheless, we tried to eliminate bias in our interviews by asking respondents to relay the typical behavior of firm representatives at the trade fair. Many of the questions were phrased in a way that would elicit a firm-centered response from our respondents, rather than a description of their individual perspectives, impressions or experiences. As a result of this approach, we are quite confident that the findings presented here represent critical patterns of firm-level behavior.

Still, because our study is designed with an exclusive focus on exhibitors, we cannot comment on the broader nature of visitors' participation objectives and knowledge creation processes. Previous observations suggest, however, that exhibiting firms act simultaneously as exhibitors and visitors during trade fairs, in that they obtain valuable information regarding products, technologies and their specific market (SCHULDT/ BATHELT 2011). Based on this perspective, we believe that our results speak to a majority of the participants at trade fairs. If anything, we expect that the overlap of visitors in the global cycle of lighting fairs is even smaller than that of exhibitors. What this means is that exhibiting firms frequently acquire important information by scanning the other exhibits and interacting with different trade fair participants. It is the focus on such knowledge processes that forms the basis of the present study.

In approaching potential respondents, we tried to ensure sufficient representation of the structure and diversity of the trade fairs in question. We did this, first, by dividing the exhibition space into segments based on distinct product/technology groups and, second, by choosing randomly within each segment - while some key accounts (i. e. industry leaders) were approached directly. We conducted a total of 86 interviews across the two North American trade fairs, with a rejection rate of $18 \%$ (Tab. 1).

Tab. 1: Interview statistics at North American lighting fairs, 2008/2009

\begin{tabular}{lcccc} 
& \multicolumn{2}{c}{ Interviews conducted } & \multicolumn{2}{c}{ Rejections } \\
Trade fair & Number & Share & Number & Rate \\
\hline IIDEX, Toronto & 31 & $36 \%$ & 7 & $18 \%$ \\
LFI, New York & 55 & $64 \%$ & 12 & $18 \%$ \\
\hline Total & 86 & $100 \%$ & 19 & $18 \%$ \\
\hline
\end{tabular}

Notes: LFI = LightFair International; $I I D E X=I I D E X / N e o C o n$ Canada

In the end, our interviews at the trade fairs covered a wide range of firm representatives, including owners, CEO, engineers, technicians, regional managers and sales representatives. Yet, as previously mentioned, we interviewed the most senior-level person available whenever possible. In terms of length, each semi-structured interview took approximately 10 to 15 minutes. The questionnaire format was separated into multiple parts, and we used several different, partially overlapping questionnaires. All of these questionnaires included questions designed to tap into the nature of exhibitors' interactions with certain agent groups, including customers, competitors, suppliers and other multipliers, with different questionnaires asking respondents to focus on different agents. All interviews began by asking respondents to ar- 
ticulate their main reasons for participating in the trade fair, list other trade fairs they usually attend and describe the focus and perceived role of innovation at the trade fair. There was also a generic section at the end of each questionnaire to gather background information on the firms, including size, structure and geographical origin.

Based on these semi-structured interviews, we developed two typologies for the purpose of discussing the knowledge circulation processes that take place within the trade fair cycle of the lighting industry. The participants' responses gave us direct insights into the goals of firms in attending these events and their practices of generating and sharing knowledge about innovations. From the interview transcripts, we developed two typologies by dividing the responses of firm representatives into a discrete number of categories that cover the extremes as well as elements of the continuum of participation goals and knowledge-exchange practices. This was done through an iterative process during which firms were carefully assigned to broader types in a series of consecutive stages. In the end, we defined and summarized general descriptors for the firm types.

The first typology classifies the types of participation goals into four categories: type 1 - industry shaping; type 2 - industry reproducing; type 3 - ambiguous and diverse; and type 4 firm boosting. The second typology focuses on innovation/knowledge-creation practices and distinguishes four types: type 1 - innovation leaders; type 2 - active innovation seekers; type 3 -impromptu innovation explorers; and type 4 - passive innovation reviewers. Taken together, the two typologies allow us to draw meaningful analytical distinctions among the different exhibitors' goals and knowledge practices across the trade fairs. These are described in the following section.

\section{Results and discussion}

The results of our study offer valuable insights into exhibitors' participation goals and the nature of knowledge exchange processes at trade fairs. These findings raise important issues regarding the conceptualization of trade fairs as FCE, as well as their perceived cyclical character. We developed two typologies of exhibitors according to their goals of participation and the interaction and knowledge-creation practices observed. While revealing different types of behavior that can be identified at many events, the two typologies allow for a more in-depth description of the nature of the trade fairs and allow us to draw conclusions regarding the ways in which they shape their industry/technology field and how they are connected with each other.

\section{Goals of participation}

Despite their similar focus on the lighting industry, the two main trade fairs examined are remarkably different in character and appeal to different audiences. Whereas IIDEX has an eclectic product focus and is clearly oriented towards the Canadian market, LFI has a more decided emphasis on lighting and a broader international reach. In 2008, the participants at IIDEX suggested that the eclectic character of the event provided them with multiple opportunities to connect with different people, mainly from within the region of Southern Ontario. For many of these regional firms, IIDEX represented an important venue for connecting with existing customers and presenting current production programs. In keeping with its general character, IIDEX participants were mostly young, small to medium-sized firms. For these firms, the trade fair was a key event for stimulating interest in their products and served as an opportunity to connect with their home market. In terms of the goals of participation, it is not surprising that a variety of motivations were identified from the interviews. This is simply because firms in the lighting industry (like in any other industry) are fundamentally heterogeneous, following different strategies, developing different goals and holding different expectations. We were able to identify four types of firms according to the goals of participation at both North American trade fairs (Tab. 2):

Type 1: Industry shaping. At the most determined end of the goals spectrum $(12 \%$ of the firms interviewed), exhibitors clearly stated that their primary objective of participation was the introduction of new technological innovations. The respondents that fell into this category were able to set this goal aside from other potentially competing goals, unlike type 3 respondents, and some directly tied the presentation of innovations to the future development of the industry or the establishment of industry trends. As such, these exhibitors are classified as those intending to shape the industry through their exhibits. 
Tab. 2: Typology of exhibitors at North American lighting trade fairs by goals of participation, $2008 / 2009$

\begin{tabular}{|c|c|c|c|c|}
\hline Category & $\begin{array}{c}\text { Type } 1 \\
\text { Industry shaping }\end{array}$ & $\begin{array}{c}\text { Type } 2 \\
\text { Industry reproducing }\end{array}$ & $\begin{array}{c}\text { Type } 3 \\
\text { Ambiguous and diverse }\end{array}$ & $\begin{array}{c}\text { Type } 4 \\
\text { Firm boosting }\end{array}$ \\
\hline Description & $\begin{array}{l}\text { Main reason for } \\
\text { participating to } \\
\text { introduce new } \\
\text { technological } \\
\text { innovations/de- } \\
\text { velop new trends }\end{array}$ & $\begin{array}{l}\text { Main reason for par- } \\
\text { ticipating to acquire } \\
\text { new ideas and infor- } \\
\text { mation that may be } \\
\text { applied in own pro- } \\
\text { duction context }\end{array}$ & $\begin{array}{l}\text { Reasons for participat- } \\
\text { ing are diverse and of- } \\
\text { ten ambiguous }\end{array}$ & $\begin{array}{l}\text { Reasons for participating } \\
\text { are mainly oriented to- } \\
\text { ward sales or promotion- } \\
\text { al activities }\end{array}$ \\
\hline \multirow[t]{2}{*}{ Firm interview ID } & $\begin{array}{l}\text { LFI } 07,08,13 \text {, } \\
35,38,40,49 \text {, } \\
53\end{array}$ & $\begin{array}{l}\text { LFI } 03,16,18,25 \text {, } \\
27,31,51\end{array}$ & $\begin{array}{l}\text { LFI } 05,10,21,29,32 \text {, } \\
39,47,52,54\end{array}$ & $\begin{array}{l}\text { LFI } 01,02,04,06,09, \\
11,12,14,15,17,19,20, \\
22,23,24,26,28,30,33 \text {, } \\
34,36,37,41,42,43,44, \\
45,46,48,50,55\end{array}$ \\
\hline & IIDEX 06, 20 & IIDEX 01,07 & $\begin{array}{l}\text { IIDEX } 02,03,05,08, \\
09,10,11,12,14,15, \\
17,19,22,23,24,25, \\
26,27,28,29\end{array}$ & $\begin{array}{l}\text { IIDEX 04, 13, 16, 18, } \\
21,30,31\end{array}$ \\
\hline Number of firms & 10 & 9 & 29 & 38 \\
\hline Share of total $(\mathrm{n}=86)$ & $12 \%$ & $10 \%$ & $34 \%$ & $44 \%$ \\
\hline
\end{tabular}

Notes: LFI = LightFair International; IIDEX =IIDEX/NeoCon Canada

Type 2: Industry reproducing. The exhibitors in this category ( $10 \%$ of the firms) were as clear as type 1 firms about the central role of innovation at trade fairs. Yet, their primary purpose for participating was less about introducing their own latest technologies than about acquiring ideas and innovations from others to be later incorporated into their own production contexts. Many of these respondents used the words "education" or "learning" in describing their main goals. And while some of these exhibitors had a relatively systematic or structured approach to scanning the fair's exhibits, others suggested that they would simply be able to recognize a useful new technology or innovation when they came across it (BATHelt/GiBson 2013). These firms were classified as participating actively in the reproduction of their industry field.

Type 3: Ambiguous and diverse. These types of exhibitors (34\% of the firms) were characterized by a considerable degree of diversity and/or ambiguity in terms of their goals. Respondents identified several participation goals, including expansion-oriented goals, acquiring new partners, maintaining or building the firm's image, obtaining an overview of the market, reconnecting with like-minded people in the industry, meeting customers (new or existing), or just "seeing what's new" in the industry. The behav- ior of these exhibitors seemed to be lacking the degree of dedication and commitment, characteristic, for instance, of type 1 firms. Sometimes respondents would state a couple of broadly related goals in one part of the questionnaire and then bring up different ones when answering another question. In short, these respondents either could not identify a single overarching goal or suggested that it "depends on the occasion".

Type 4: Firm boosting. Whereas all respondents were understandably interested in securing their own firm's future position/status in the industry, those that fell into this final category ( $44 \%$ of the firms) were the most assertive and unequivocal in identifying sales or promotional activities as the main objective of participation. Whereas sales-oriented activities in this sense included the generation of new leads, the promotional activities were mainly focused on enhancing product awareness and/or branding issues. These respondents either did not mention innovation or they downplayed its significance for them in the given context. As a consequence, these firms neither showed a focused interest in the changes of their field, nor did their actions have a substantive impact on the field.

While each type was identified at the two North American fairs, they played out quite differently 
during the events. Whereas sales and contract negotiations could not be described as the primary focus of exhibitors at IIDEX, the presentation or introduction of new technological innovations was also not the driving force behind participation for most of the firms at this event (Tab. 2). For many exhibitors, it was quite difficult to determine an overarching purpose for participation at the trade fair. Indeed, exhibitors' goals of participation were diverse and often quite ambiguous (BATHELT/GIBSON 2013). They utilized the fair in various ways as an event for image-building, gaining an overview of the industry, expansion into new regions/markets, acquiring new partners, as well as for general networking and information-gathering and/or exchange. For some firms, the goals of participation were guided by the nature of the trade fair itself. As described by the owner of a small lighting components firm, "[t]here are different types of trade fairs. There are those that focus on displaying the most recent products; there are those where the focus is mainly on trying to acquire customers; and there are trade fairs where existing products are shown and you get an overview of the industry as well as trying to pick and steal ideas from others." The diversity of participation goals and corresponding events is also well captured in the following comment by a lighting fixtures design company: "There are different kinds of trade shows within the industry. This one is more targeted towards people who design buildings. There are other, more regionalized shows and then there are more vertical shows, which are much closer defined in terms of the people that attend. Examples would be a utilities or municipal show, where only street lighting is shown. These are targeted toward more specific kinds of products. This one is a little broader." Reflecting the eclectic nature of the event, the vast majority of the exhibitors at IIDEX (20 of 31 , or $65 \%)$ were unable to pinpoint a single overarching goal of participation (Tab. 2). In doing so, they clearly differentiated IIDEX from other events in the industry and emphasized its uniqueness in relation to such events.

Compared to IIDEX, LFI has a broader spatial reach in terms of the audience it attracts, with many international exhibitors from Europe or China. Similar to IIDEX, participants at LFI comprise a wide range of industry-related professionals, including architects, designers, engineers, urban planners, public utility representatives and energy specialists (LightFair Interna- tional 2009b). It is important to note, however, that these participants are not generally seen as key attendants of the trade fair. With respect to its target audience, most exhibitors in 2009 emphasized the centrality of American distributors and retail firms. In general terms, LFI is characterized by a broader array of small, medium-sized and larger firms than IIDEX (BATHELT et al. 2014). On average, exhibiting firms at LFI are also older than those at IIDEX. LFI may thus be characterized as a trade fair where established firms come to create business and market their products. Compared to IIDEX, LFI had a stronger import and general sales focus, with over half of respondents in 2009 (31 of 55 firms or $56 \%$ ) falling into the firm-boosting category (Tab. 2). In terms of its main focus, LFI had the characteristics of a key event that provides lighting firms with opportunities to connect with the broader American market. Exhibitors at the event were focused on making direct customer contact and meeting with the marketing personnel of other firms, traders, consumer chain representatives and large-scale buyers. Though not much larger than IIDEX, there was a much stronger market orientation at LFI. For many respondents, the main reason for participating at the event was to engage in customer interaction, such as making contact with potential and existing customers in North America. Gaining/maintaining access to or a presence in the North American market was a central objective for most exhibitors.

The situation at $\mathrm{L}+\mathrm{B}$ provides an interesting contrast to the two North American cases (BATHELT/ SCHULDT 2008). Bringing together a truly global audience, with German exhibitors and visitors representing only a minority of the participants, $\mathrm{L}+\mathrm{B}$ is widely recognized as the global flagship event in the industry with respect to inspecting and discussing new developments in technologies, markets and government regulations. The event attracts national market leaders from all around the world, providing unparalleled opportunities for firms to target international markets. It is not surprising that the participants at $\mathrm{L}+\mathrm{B}$ are the most internationalized and on average the largest, oldest and most well-established firms across the three lighting fairs examined here (BATHELT et al. 2014).

While it is true that the overall sales agreements at L+B in 2004 amounted to a much higher total than at IIDEX or LFI due to the size of the event, sales-oriented activities were clearly not the main focus of exhibitors. Instead, L $+B$ rep- 
resented a global hub where participants from across the globe came to acquire information about recent developments, learn about future trends in their specific technology field and discuss the dynamic changes in the industry with their global colleagues and peers. Even firms lacking strong market shares in Germany or Europe took part in the event's highly-sophisticated buzz environment, connecting with their customers and suppliers from North and South America or Asia. Interestingly, the atmosphere at $\mathrm{L}+\mathrm{B}$ was more relaxed and less business-like than at IIDEX and LFI. Participants spent time talking to one another, enjoying snacks or beverages at other booths and even discussed with competitors their impressions about new technologies, markets, industry gossip and so on (BATHELT/SCHULDT 2008).

To summarize, each of the three lighting fairs revealed a different focus and purpose, which led them to attract different types of firms and firm representatives. Without denying certain overlaps and cross-references among the events, a relatively small proportion of firms were regular participants at all three fairs. And when the firms did attend other lighting fairs, they were often represented by different specialists, typically a representative from a local branch or partner. Between L+B and LFI, we did witness some overlap in terms of large firms, and particularly market leaders. But only about half of the interviewees at LFI said that they had ever attended the flagship event $\mathrm{L}+\mathrm{B}$; the share of interviewees at $\mathrm{L}+\mathrm{B}$ that referred to LFI was even much lower. We also noticed some overlap between LFI and IIDEX; however, only a few interviewees at LFI felt that IIDEX was a relevant event for them. Foreign firms were the least likely to see the value of participating in a Canadian trade fair due to the small size of the Canadian market, which many felt could be adequately covered by participating at LFI. When conducting our research, we made a point of visiting the booths of the same firms during the different fairs, but rarely came across the same firm representatives. While this latter finding is admittedly derived from anecdotal observations, it nevertheless raises important questions regarding the conceptualization of trade fairs as cyclical events, built on cumulative knowledge creation among the same groups of firms and participants. ${ }^{4}$ While there are similar topics that are presented at related fairs and while knowledge clearly develops through these events, trade fairs in a specific industry or technology field are far from establishing a linear sequence of "networks of fairs" as suggested by MOERAN (2011).

Whereas the three events studied here provide mere glimpses of the industry's product and technology structure, both of which continue to evolve over time, there was little evidence of direct, substantive knowledge flows between the fairs. Instead, the events represented integral components of the multi-layered knowledge flows within the lighting industry, which were complemented by industry reports, specialized publications, regular producer-user interaction, Internet updates and the like. We turn now to explore more deeply the nature of interaction and knowledge-creation practices at the lighting fairs studied.

\section{Interaction and knowledge-creation processes}

The abovementioned variation in the purposes, foci and audiences of the three trade fairs led to important differences in exhibitor interaction and knowledge circulation practices. In a general sense, $\mathrm{L}+\mathrm{B}$ may be said to establish a temporary environment that gives participants an opportunity to obtain a comprehensive overview of innovative product and technology developments in the industry, whereas LFI allows for a broader overview of market trends. Unlike either of these fairs, IIDEX offers representation of limited market segments, with only a selection of product groups displayed, notably in an eclectic and seemingly arbitrary form, and a marginal role for design innovations. From these different foci, the contexts for meetings and get-togethers at these events were associated with markedly different communication patterns. According to the interviews conducted, we are able to distinguish four types of exhibitors related to innovation and knowledge-creation practices ${ }^{5}$, with clear differences between the lighting fairs investigated (Tab. 3 ):

Type 1: Innovation leaders. At the clearest and most assertive end of the spectrum of knowledge-creation practices, exhibitors always presented new technological innovations at the trade fair and sometimes used the trade fair as a deadline or target for developing such innovations ( $10 \%$ of the firms interviewed). Respondents in this category documented a very high level of interaction with other participants at the fair - be they customers, suppliers, competitors or other multipliers. The nature of these discus- 
Tab. 3: Typology of exhibitors at North American lighting trade fairs by innovation/knowledgecreation practices, 2008/09

\begin{tabular}{|c|c|c|c|c|}
\hline Category & $\begin{array}{l}\text { Type } 1 \\
\text { Innovation } \\
\text { leaders }\end{array}$ & $\begin{array}{c}\text { Type } 2 \\
\text { Active } \\
\text { innovation seekers }\end{array}$ & $\begin{array}{c}\text { Type } 3 \\
\text { Impromptu } \\
\text { innovation explorers }\end{array}$ & $\begin{array}{c}\text { Type } 4 \\
\text { Passive } \\
\text { innovation reviewers }\end{array}$ \\
\hline Description & $\begin{array}{l}\text { Always present new } \\
\text { innovations at fairs } \\
\text { in an active and } \\
\text { structured way; } \\
\text { high level of inter- } \\
\text { action with other } \\
\text { participants; focus } \\
\text { of such interactions } \\
\text { often directly relat- } \\
\text { ed to innovation }\end{array}$ & $\begin{array}{l}\text { Do not always pres- } \\
\text { ent new innovations } \\
\text { but actively search } \\
\text { for them at fairs; in- } \\
\text { teraction with other } \\
\text { participants is high } \\
\text { but focus often on } \\
\text { practical/technical } \\
\text { knowledge and/or in- } \\
\text { dustry best practices }\end{array}$ & $\begin{array}{l}\text { Emphasize the impor- } \\
\text { tance of innovation at } \\
\text { fairs in general and } \\
\text { spend time exploring } \\
\text { other exhibits; inter- } \\
\text { action with other par- } \\
\text { ticipants is moderate } \\
\text { to high, but quite } \\
\text { diverse and unstruc- } \\
\text { tured in nature }\end{array}$ & $\begin{array}{l}\text { Innovation not con- } \\
\text { sidered very import- } \\
\text { ant and/or not active } \\
\text { in exploring other } \\
\text { exhibits for new } \\
\text { ideas; interaction } \\
\text { with other exhibitors } \\
\text { is limited and/or } \\
\text { superficial }\end{array}$ \\
\hline \multirow[t]{2}{*}{ Firm interview ID } & $\begin{array}{l}\text { LFI } 07,08,10,13 \text {, } \\
38,40,53\end{array}$ & $\begin{array}{l}\text { LFI } 03,04,05,06, \\
16,18,20,25,26,27, \\
28,31,33,35,39,42, \\
45,47,50,51,55\end{array}$ & $\begin{array}{l}\text { LFI } 01,09,11,12, \\
14,15,19,22,23,24, \\
29,36,37,41,43,44, \\
46,48,49,52,54\end{array}$ & $\begin{array}{l}\text { LFI } 02,17,21,30 \text {, } \\
32,34\end{array}$ \\
\hline & IIDEX 06,20 & $\begin{array}{l}I I D E X \quad 01,03,07,09 \\
12,15,25,26,27\end{array}$ & $\begin{array}{l}I I D E X \quad 02,05,08,10 \\
11,14,17,22,23\end{array}$ & $\begin{array}{l}\text { IIDEX } 04,13,16, \\
18,19,21,24,28, \\
29,30,31\end{array}$ \\
\hline Number of firms & 9 & 30 & 30 & 17 \\
\hline Share of total $(\mathrm{n}=86)$ & $10 \%$ & $35 \%$ & $35 \%$ & $20 \%$ \\
\hline
\end{tabular}

Notes: LFI = LightFair International; IIDEX =IIDEX/NeoCon Canada

sions revolved around the latest innovations and breakthroughs in the industry.

Type 2: Active innovation seekers. Unlike type 1 firms, the exhibitors in this category $(35 \%$ of firms) did not always or even usually present new innovations at the trade fair. However, they were as clear as type 1 firms regarding the centrality of innovation at trade fairs and emphasized the importance of searching for innovations during the event. In this respect, these firms were quite active and deliberate in their search behavior. Interactions with other participants were also high, but discussions did not always focus exclusively on new ideas or innovations; instead, they centered on issues of a more practical/technical nature, including industry best practices.

Type 3: Impromptu innovation explorers. These types of exhibitors (35\% of firms) recognized the importance of innovation at the trade fair, but were much less systematic and active than their type 2 counterparts in terms of searching the other exhibits. They described a process of just "wandering about" to see what was new or interesting to them (BATHELT/GiBSON 2013). They were very open-minded in their explorations, but did not always set aside the same amount of time for these practices as type 2 respondents. Interactions with other participants were moderate to high but again less structured and often involved a diverse range of topics.

Type 4: Passive innovation reviewers. In contrast to the other three types, the exhibitors that fell into this category ( $20 \%$ of the firms) did not seem to fully appreciate or assign much weight to the presentation of new innovations at the trade fair. These firms had a tendency to be more inwardly focused and concerned with salesoriented or promotional activities. They either did not have time to explore the other exhibits or did not prioritize this activity. Interactions with other participants were, thus, quite limited and when they did occur seemed to be superficial in nature.

While all types were identified at both North American lighting fairs, they played out in different ways. With regards to producer-user interactions, innovation and the nature of knowledge exchange, there were distinct differences among the lighting fairs. Compared to $\mathrm{L}+\mathrm{B}$, which was an active driver of the industry's innovation dynamics, we could not characterize LFI and IIDEX as leaders in the introduction of new 
products and technologies. Although a higher proportion of respondents at LFI than IIDEX ( $13 \%$ vs. $6 \%$ of the firms, respectively) fell within the innovation leaders category, 42 of the 55 LFI exhibitors interviewed clustered towards the center of the spectrum as active innovation seekers ( $38 \%$ of the firms) and impromptu innovation explorers (38\% of the firms). Rather than identifying a clear pattern of presenting new technologies and discussing the potential impact of such innovations, as was the case with type 1 respondents 6 , type 2 and type 3 respondents were the recipients and preservers of new ideas and innovations. As the CEO of a medium-sized design firm phrased it, "we just want to see what is out there in terms of new products, new innovations. We are trying to see whether what we have is behind or more advanced and how we stack up compared to the competition."

The difference between type 2 and type 3 exhibitors was not particularly notable in our study, except for the fact that the active seekers (type 2) demonstrated more structure and spent more time searching through the exhibits and interacting with other participants than the type 3 impromptu explorers (BATHELT/GIBSON 2013). Aside from this, the former group was also better able to pinpoint the nature of their exchanges, often noting practical/technical information or knowledge pertaining to industry best practices as the focal point of their exchanges. The following quote nicely captures this interaction type: "One of the most important things is to learn about new technological developments that we could potentially incorporate into our products in the future. I have several goals: to educate myself as to what is new, and to find the latest thinking in product design and development but also in technology. Also, we want to know what our competitors are doing in that respect. So when we walk the floor, we skim through the presentations and booths, and if we spot something interesting, we focus on that. You can see just by looking at a product if it is doing something unique, or from a design perspective whether there is new thinking or a design direction involved. There are also certain manufacturers that are known for technical innovation who we pay more attention to." In comparison, type 3 respondents were much less certain in their responses regarding the focus of their discussions with other participants. While they put a premium on the transmission of innovation at the trade fair, the content of their interactions was often free-flowing and would often "depend on the situation".
At IIDEX, interactions with trade fair participants less commonly involved conversations about specific transaction procedures or new technological developments; on the whole, they had a tendency to be more generic in character. While over three-quarters of LFI exhibitors (42 of the 55 or $76 \%$ of the firms) fell into the innovation seeking categories (type 2 or type 3 ), the largest single grouping of respondents at IIDEX ( 11 of 31 or $35 \%$ of the firms) fell into the passive innovation reviewers type. These exhibitors represent the least engaged type of trade fair participants with respect to innovation and knowledge-creation practices. Although these exhibitors often knew visitors from former meetings and existing customer interaction, which allowed for some feedback about the products, respondents were unable to describe specific cases of how such contacts related to innovation or problem-solving in the past. When asked whether they sometimes come up with new ideas when talking to customers, these exhibitors replied "no" or "very rarely".

At LFI, there was a great deal of industry buzz regarding light-emitting diodes (LEDs) and other energy saving lighting solutions associated with the transition from the classical light bulb to new energy-saving lighting solutions. Although the the decision of European Union (EU) to phase out the classical light bulb in the European market by the end of 2012 was known long before IIDEX 2008 - a decision that was driven by recognition of the classical light bulbs' substantial inefficiencies including a general loss of energy (FROMMBERG 2009a, 2009b) - did not seem to have the same impact at this event as it did at LFI. From an industry perspective, the change in legislation regarding the classical light bulb spawned a new wave of technological innovation and created new opportunities for a wide range of design innovations. These innovations involved the use of new materials, which presented unique architectural opportunities in daylight product services, efficient lighting, decorative lighting fixtures, and interior and exterior luminaries. Such innovative solutions marked the exhibits at LFI in New York and became central to the event's buzz. According to many interviewees, this particular innovation dynamic made attendance at LFI even more significant in 2009 than in previous years.

In general, the atmosphere at LFI was better at fostering exhibitor interaction and knowledge exchange than at IIDEX. The buzz at this event 
was palpable and exhibitors and visitors alike were busy moving from exhibit to exhibit, as well as engaging with the crowds of visitors that congregated in the hallways and in local meeting areas, such as food courts. The atmosphere at IIDEX was comparatively more sterile, brought in a smaller crowd, and was generally slower and less lively in character. In fact, there seemed to be something of a nervous energy among many of the exhibitors at IIDEX when they looked around and talked to the visitors who passed by their stands. While many exhibitors at LFI offered visitors free snacks and beverages, this type of host-like behavior was all but absent at IIDEX.

Despite the above-mentioned differences, neither IIDEX nor LFI was designed in a way that came close to the interactive, communicative atmosphere experienced at $\mathrm{L}+\mathrm{B}$. At this latter event, visitors actively wandered around, engaging in conversations with other visitors, directly approaching exhibitors, and frequently returning in a back-and-forth fashion to exhibits where they came across something interesting a few hours earlier. This pattern of interaction was accompanied by more or less focused discussions regarding the details and specific properties of newly presented innovation. $\mathrm{L}+\mathrm{B}$ was also characterized by a highly social and hospitable environment; it was common for exhibitors to enjoy a glass of wine or beer with their competitors towards the end of the day at near-by booths, and many made dinner plans with potentially important new customers they met during the fair (BATHELT/SCHULDT 2008). In terms of participants, $\mathrm{L}+\mathrm{B}$ attracted a diverse assortment of leading managers, as well as notable groups of engineers, designers and the global press. These participants were rarely just focused on buying products; rather, they actively engaged in the collective sense-making processes that shape the field's technological development. They were involved in complex interactions with a wide range of participants at the fair, including new and existing customers, partners and suppliers, as well as competitors, media representatives and industry observers. Participation at $\mathrm{L}+\mathrm{B}$ was, therefore, instrumental in providing firms with the necessary opportunities to accurately evaluate their market and technology positions among global peers.

As Bathelt/Schuldt $(2008,864)$ demonstrate, $\mathrm{L}+\mathrm{B}$ produces a complex knowledge ecology "that is highly conducive to processes of pipeline formation and knowledge creation. The participants of these events are surrounded by a densely knit web of specialized information and knowledge flows that cannot be ignored. The multidimensional structure of this 'global buzz' enables firms to get an overview of what is going on and scrutinize the trends visible in the exhibits of competitors and complementary firms. Firms can evaluate their own activities and achievements by comparing themselves to others and make decisions about future strategies and products."

Participants do not need to have direct contact with specific artifacts to acquire valuable information about new developments. The event's buzz makes the diffusion of industry news about innovations inevitable (BATHELT/SCHULDT 2010). This buzz creates a situation in which both visitors and exhibitors can make informed choices about which exhibits to focus their attention on. It also helps them develop a solid grasp of these developments. As indicated by many interviewees, this knowledge is crucial in adjusting firm strategies and designing future innovation processes.

\section{Conclusion}

The present study aims to address the conceptual ambiguity surrounding recent debates about knowledge-creation practices in temporary spaces. In particular, we discuss the utility of concepts such as FCEs and cyclical/temporary clusters in explaining knowledge generation processes at trade fairs. While the concept of FCEs remains somewhat vague, its explanatory power is most convincing in describing discrete processes of field configuration, such as significantly shifting a technology or industry field. Such shifts do not occur at the majority of trade fairs, however, due to the decentralized nature of communication and knowledge exchange processes. And, while learning processes are often cumulative and incremental in character, they do not involve continuous, fluid processes of knowledge circulation as in an ideal-type cyclical cluster context. These findings have been illustrated through an empirical analysis of three events in the global trade fair cycle of the lighting industry: LFI in New York, IIDEX in Toronto and $\mathrm{L}+\mathrm{B}$ in Frankfurt/Main.

Based on semi-structured interviews and systematic observations, we found substantial differences in the goals of the participants and the 
knowledge circulation practices operating within and among these events. Of the fairs studied, $\mathrm{L}+\mathrm{B}$ is clearly the innovation leader and serves as a key place for global firms in the lighting field to meet and discuss the latest technological, market, and regulatory developments. IIDEX, on the other hand, is a regional event that attracts a limited market and serves as a place where small and young firms in the industry can explore their core markets and make new contacts. Although LFI reveals more extensive interaction patterns than IIDEX, the focus of this event appears to be on market access and sales-relevant contacts with wholesalers, retailers, and other customer groups.

First, we discovered a minor degree of overlap in terms of goals of participation, and a limited number of industry leaders that were represented at all fairs. In general, however, we did not identify strong connections among the events. Most often, the events attracted different groups of participants who had varied goals and expectations. And, for the most part, it was uncommon for the same firm representatives to participate across the different events. The diverse character and contrasting purposes of the trade fairs, which fostered differences in the nature of interactions, undermined processes of direct knowledge exchange between the events. Taken together, our findings suggest that these events are not part of a continuous cycle of trade fairs that stimulates on-going, seemingly boundless knowledge creation in the lighting field.

Second, we did not find discrete field configuration activities, suggesting that the concept of FCEs does not sufficiently explain knowledge-creation practices at national/international trade fairs. The events studied do not trigger or direct discontinuous developments in the lighting industry in a deliberate way. Instead, the processes identified suggest that trade fairs provide partially overlapping and partially different, sometimes consistent and sometimes contradictory, projections about decentralized market and technology developments associated with national and industry-wide regulations and standards. While the trade fairs were not designed in a predictable way, most participants were not surprised about what they found during the event. This is largely due to their involvement in field structuration, which allows them to access knowledge about the field on a daily basis via diverse communication channels. In this way, trade fairs may be better viewed as events that contribute to the field's on-going reproduction, as opposed to discontinuously shaping or configuring it.

As such, trade fairs more accurately reflect a distinct middle-ground that facilitates decentralized field reproduction activities through temporary get-togethers in an industry or technology field. They are permanently situated between, but not close to, the extreme types of discontinuous, organized field configuration and of continuous, seemingly boundless knowledge circulation.

\section{Acknowledgements}

The arguments presented in this paper, to which both authors contributed equally, draw, in part, from insights and discussions in BATHELT et al. (2014). We are grateful to Ian Bichmann for providing superb research support, to the editors for their strong encouragement and to one reviewer for providing a detailed critique. Financial support from the $\mathrm{So}$ cial Sciences and Humanities Research Council (SSHRC) of Canada is greatly appreciated (File Number 410-20072167).

\section{Notes}

1 We are aware that some of the more recent literature on FCEs has aimed to further develop the concept by emphasizing both field evolving and maintaining characteristics (e.g. SCHÜSSLER et al. 2014). One of the challenges with this approach, however, is that it leads us away from the most innovative element of the FCE concept. It is not our intention to discuss the FCE literature in all its facets; rather, we focus on what seems to be the dominant interpretation and, in our view, the most compelling aspect of the concept.

2 We do not wish to introduce a new concept, as existing concepts that describe how fields are being reproduced or structurated can be usefully employed. GIDDENS' (1984) structuration theory can be particularly useful in such analyses (see also ANAND/WATSON 2004). Field reproduction aims to evoke the dynamics of the structuration process. This is similar to the notion of "field maintenance" used by SCHÜSSLER et al. (2014), although "field reproduction" explicitly aims to avoid associations with maintaining the status quo.

3 Research at L+B was conducted much earlier in 2004 and consisted of 142 interviews (BATHELT/SCHULDT 2008). Although these interviews had a somewhat different focus, the same main areas of interest were covered.

4 It appears that such cyclical clusters may be best developed in particular creative/design-intensive industries, such as the production of high-end furniture (e.g. PowER/JANSSON 2008), or in established specialized capitalgoods industries.

5 When comparing both typologies (Tab. 2 and 3), there seems to be a clear association between the goals of 
trade fair participation and the innovation and knowledge generation patterns observed. Upon closer investigation, however, the correspondence of firms in both classifications is lower than the description of the types would let us expect.

6 For example, the president of one firm described the knowledge and interaction processes as follows: "We first demonstrated an energy saving product in Frankfurt some time ago to a huge audience. Now everybody uses these energy saving measures - we really made a name for ourselves with it back then."

\section{References}

Allix, A. (1922): The geography of fairs. Illustrated by oldworld examples. In: Geographical Review, 12, 532-569.

ANAND, N./ Jones, B.C. (2008): Tournament rituals, category dynamics, and field configuration. The case of the Booker prize. In: Journal of Management Studies, 45, 1036-1060.

ANAND, N./WATSON, M.R. (2004): Tournament rituals in the evolution of fields. The case of the Grammy Awards. In: Academy of Management Journal, 47, 59-80.

Bathelt, H. / Gibson, R. (2013): Learning in 'organized anarchies'. Technological search processes and knowledge flows at international trade fairs. In: Regional Studies, 47. (forthcoming, doi:10.1080/00343404.2013.783691).

Bathelt, H. / Golfetto, F. / Rinallo, D. (2014): Trade shows in the globalizing knowledge economy. Oxford.

BAthelt, H. / SchuldT, N. (2008): Between luminaires and meat grinders. International trade fairs as temporary clusters. In: Regional Studies, 42, 853-868.

BAthelt, H. / SchUldT, N. (2010): International trade fairs and global buzz. Part I: Ecology of global buzz. In: European Planning Studies, 18, 1957-1974.

Borghini, S. / Golfetto, F. / Rinallo, D. (2004): Using anthropological methods to study industrial marketing and purchasing: An exploration of professional trade shows. Copenhagen. (Presented at the Industrial Marketing Purchasing Conference, Copenhagen; Internet: http://www.impgroup.org/paper_view.php?viewPaper=4505, Dec. 2, 2013). Borghini, S. / Golfetto, F. / Rinallo, D. (2006): Ongoing search among industrial buyers. In: Journal of Business Research, 59, 1151-1159.

Cohendet, P. / Héraud, J.-A. / Llerena, P. (2013): A microeconomic approach to the dynamics of knowledge creation. In: Meusburger, P. / Glückler, J. / El Meskioui, M. (Eds.): Knowledge and economy. Klaus Tschira Symposia. Heidelberg, 43-59. (Knowledge and Space 5).

Entwistle, J. / Rocamora, A. (2006): The field of fashion materialized. A study of London Fashion Week. In: Sociology, 40, 735-751.

FrommberG, L. (2009a): Birnen-Problem (Bulb problem). In: Frankfurter Rundschau, 28. Aug. 2009, 18.

FrommBerG, L. (2009b): Licht aus (Light off). In: Frankfurter Rundschau, 28. Aug. 2009, 18-19.

GARUD, R. (2008): Conferences as venues for the configuration of emerging organizational fields: The case of co- chlear implants. In: Journal of Management Studies, 45, 1061-1088.

GidDENS, A. (1984): The constitution of society. Outline of the theory of structuration. Cambridge.

Hardy, C. / Maguire, S. (2010): Discourse, field-configuring events, and change in organizations and institutional fields. Narratives of DDT and the Stockholm Convention. In: Academy of Management Journal, 53, 1365-1392.

IIDEX/NeoCon Canada (2008a): IIDEX Mediaflash. Toronto (Press release, Internet: http://www.iidexneocon. com/2008/index.php/newsletter/, Sep. 2, 2008).

IIDEX/NeoCon Canada (2008b): 2008 IIDEX/NeoCon Canada Official Show Guide. Toronto. (Brochure).

LAMPEL, J. / MEYER, A.D. (2008): Field-configuring events as structuring mechanisms. How conferences, ceremonies, and trade shows constitute new technologies, industries, and markets. In: Journal of Management Studies, 45, 10251035.

LightFair International (2009a): Official on-site directory. New York. (Brochure).

LightFair International (2009b): General exhibit information. New York. (Internet: http://www.lightfair.com/lightfair/V40/index.cvn?id=10191, April 21, 2009).

Maskell, P. / Bathelt, H. / MAlmberg, A. (2006): Building global knowledge pipelines. The role of temporary clusters. In: European Planning Studies, 14, 997-1013.

MCInERney, B. (2008): Showdown at Kykuit. Field-configuring events as loci for conventionalizing accounts. In: Journal of Management Studies, 45, 1089-1116.

MefFert, H. (1993): Messen und Ausstellungen als Marketinginstrument (Trade shows and exhibitions as a marketing tool). In: Goehrmann, K. E. (Ed.): Polit-Marketing auf Messen (Marketing Policy at Trade Shows). Düsseldorf, 74-96. Messe Frankfurt GmbH (2004a): Light + Building. Internationale Fachmesse für Architektur und Technik vom 18. bis 22. April 2004 in Frankfurt am Main: Aussteller in Zahlen (Data Report of Exhibitors at the Light + Building from April 18 to 22, 2004). Frankfurt am Main. (Press release, April 15, 2004).

Messe Frankfurt GmbH (2004b): Light + Building, Internationale Fachmesse für Architektur und Technik vom 18. bis 22. April 2004 in Frankfurt am Main: Schlussbericht. (Final Report of Light + Building from April 18 to 22, 2004). Frankfurt am Main. (Press release, April 22, 2004).

Meyer, A. D. / GabA, V. / Colwell, K.A. (2005): Organizing far from equilibrium. Non-linear change in organizational fields. In: Organization Science, 16, 456-473.

Moeran, B. (2011): Trade fairs, markets and fields. Framing imagined as real communities. In: Historical Social Research, (36)3, 79-98.

Moeran, B. / Pedersen J.S. (2011): Introduction. In: Moeran, B./Pedersen, J.S. (Eds.): Negotiating values in the creative industries. Fairs, festivals and competitive events. Cambridge, 1-35.

MÖLlerING, G. (2010): Collective market-making at an engineering conference. Köln. (Max-Planck-Institut für Gesellschaftsforschung, MPIfG Discussion Paper 10/2).

Norcliffe, G. / Rendace, O. (2003): New geographies of comic book production in North America. The new artisans, 
distancing, and the periodic social economy. In: Economic Geography, 79, 241-273.

Power, D. / JANSSON, J. (2008): Cyclical clusters in global circuits. Overlapping spaces and furniture industry trade fairs. In: Economic Geography, 84, 423-448.

RAO, H. (1994): The social construction of reputation. Certification contests, legitimation, and the survival of organizations in the American automobile industry: 1895-1912. In: Strategic Management Journal, 15, 29-44.

Rinallo, D. / Golfetto, F. (2006): Representing markets. The shaping of fashion trends by French and Italian fabric companies. In: Industrial Marketing Management, 35, 856869.

Rinallo, D. / Golfetto, F. (2011): Exploring the knowledge strategies of temporary cluster organizers. A longitudinal study of the EU fabric industry trade shows (19862006). In: Economic Geography, 87, 453-476.
Rosson, P. J. / Seringhaus, F. H. R. (1995): Visitor and exhibitor interaction at industrial trade fairs. In: Journal of Business Research, 32, 81-90.

RÜLing, C.-C. / Pedersen, S. (2010): Film festival research from an organizational studies perspective. In: Scandinavian Journal of Management, 26, 318-323.

Schuldt, N. / BAthelt, H. (2011): International trade fairs and global buzz. Part II: Practices of global buzz. In: European Planning Studies, 19, 1-22.

SChÜSSler, E. / RÜLING, C.-C. / WitTneBEn, B. (2014): On melting summits. The limitations of field-configuring events as catalysts of change in transnational climate policy. In: Academy of Management Journal, 57, 140-171.

Torre, A. / Rallet, A. (2005): Proximity and localization. In: Regional Studies, 39, 47-59. 